\title{
K15 Expression Implies Lateral Differentiation within Stratified Epithelial Basal Cells
}

\author{
Rebecca M. Porter, Declan P. Lunny, Patricia H. Ogden, Susan M. Morley, \\ W. H. Irwin McLean, Alan Evans, Dolores L. Harrison, Elizabeth L. Rugg, and \\ E. Birgitte Lane
}

CRC Cell Structure Research Group (RMP, DPL, PHO, SMM, WHIM, ELR, EBL), University of Dundee, Dundee, Epithelial Genetics Group (WHIM) and Department of Molecular and Cellular Pathology (AE), Ninewells Medical School, Dundee, ICRF Clare Hall Laboratories (DLH), Hertfordshire, and Centre for Cutaneous Research (ELR), St Bartholomew's and the Royal London Hospital School of Medicine and Dentistry, London, United Kingdom

\begin{abstract}
SUMMARY: Keratins are intermediate filament proteins whose expression in epithelial tissues is closely linked to their differentiated state. The greatest complexity of this expression is seen in the epidermis and associated structures. The critical basal (proliferative) cell layer expresses the major keratin pair, $\mathrm{K} 5$ and $\mathrm{K} 14$, but it also expresses an additional type I keratin, $\mathrm{K} 15$, about which far less is known. We have compared the expression of K15 with K14 in normal, pathological, and tissue culture contexts; distinct differences in their expression patterns have been observed that imply different regulation and function for these two genes. K15 appears to be preferentially expressed in stable or slowly turning over basal cells. In steady-state epidermis, K15 is present in higher amounts in basal cells of thin skin but in lower amounts in the rapidly turning over thick plantar skin. Although remaining high in basal cell carcinomas (noninvasive) it is suppressed in squamous cell carcinomas (which frequently metastasize). Wounding-stimulated epidermis loses K15 expression, whereas K14 is unchanged. In cultured keratinocytes, K15 levels are suppressed until the culture stratifies, whereas K14 is constitutively expressed throughout. Therefore, unlike $\mathrm{K} 14$, which appears to be a fundamental component of all keratinocytes, $\mathrm{K} 15$ expression appears to be more tightly coupled to a mature basal keratinocyte phenotype. (Lab Invest 2000, 80:1701-1710).
\end{abstract}

$T$ he epidermis is a thick stratified epithelium, which is specialized for its barrier function at the outer extremity of the body. A major part of this specialization is the compartmentalized and sequential expression of keratin intermediate filaments, which provide the necessary physical resilience to cells in this location. The predominant keratins of the epidermis are the primary keratins $\mathrm{K} 5$ and $\mathrm{K} 14$ in the proliferative basal layer and the secondary differentiation-specific keratins $\mathrm{K} 1$ and $\mathrm{K} 10$ in the suprabasal layers. Several other keratins are expressed in different parts of the epidermis and its appendages, in areas of distinct differentiation. These include the keratin $\mathrm{K} 2 \mathrm{e}$, which is widespread in the upper layers of the human epidermis (Collin et al, 1992), and K9, K6, K16, and K17, which are expressed in palmoplantar epidermis (Swensson et al, 1998). K6, $\mathrm{K} 16$, and $\mathrm{K} 17$ are also normally expressed in the hair follicles but are induced in suprabasal cells elsewhere during wound healing, tumorigenesis, and some hyperproliferative diseases, usually with a concomitant reduction in expression of $\mathrm{K} 1$ and $\mathrm{K} 10$ (Weiss et al, 1984; Wilson et al, 1994). Based on the clear function

Received July 3, 2000.

Address reprint requests to: Dr. Rebecca M. Porter, CRC Cell Structure Research Group, MSI/WTB complex, University of Dundee, Dow Street, Dundee, DD1 5EH, United Kingdom. Fax: 00441382 224117; E-mail: rmporter@dux.dundee.ac.uk of keratin filaments in reinforcing epithelial cells that has emerged from the studies of keratin mutations in skin fragility disorders, it is assumed that the regional differences in keratin expression probably reflect adaptation to different physical requirements of different body sites. Knowledge of the normal distribution patterns of keratins provides another diagnostic tool for the recognition of pathological changes when these patterns are altered.

Until recently $\mathrm{K} 15$ was considered to be a minor keratin of stratified epidermis (Moll et al, 1982). Before the advent of monospecific antibodies to $\mathrm{K} 15$, few expression studies were carried out on this keratin because human $\mathrm{K} 14$ has a similar molecular weight (50 kDa) to $\mathrm{K} 15$ and the two could only be distinguished by 2D-gel electrophoresis. Biochemical analysis had detected K15 in internal squamous epithelia (oral mucosa, larynx, esophagus, ectocervix, and vagina) and in squamous cell carcinomas derived from these tissues (Banks-Schlegel and Harris, 1984; Grace et al, 1985; Moll et al, 1983, 1984; Nelson and Sun, 1983). Elevated levels of K15 have been observed in squamous cell carcinomas of the esophagus (Grace et al, 1985), but keratinizing squamous cell carcinomas of the cervix were reported not to express K15 (Smedts et al, 1993). The bronchial epithelium of the lung and some squamous cell carcinomas of the lung have also been shown to express $\mathrm{K} 15$ by 2D polyacrylamide electrophoresis (Blobel et al, 1984). 
The incomplete story of the role of $\mathrm{K} 15$ in the epidermis has recently begun to attract renewed interest. In patients with a rare recessive Koebner form of epidermolysis bullosa simplex, a skin blistering disorder caused by the absence of expressed K14, there are no thick tonofilament bundles (typical of normal K14-containing filaments) in the epidermal basal cells (Chan et al, 1994; Rugg et al, 1994). However some "wispy" filaments were seen in the basal cells (Jonkman et al, 1996) and K15 was detected in these filaments together with $\mathrm{K} 5$. If $\mathrm{K} 15$ copolymerizes with $\mathrm{K} 5$ but does not make filament bundles, this suggests that the function of $\mathrm{K} 15$ is very different from that of $\mathrm{K} 14$.

It has now become clear that significant amounts of K15 are present in the basal layer of several stratified epithelial tissues (Lloyd et al, 1995; Waseem et al, 1999). It has even been suggested that K15 may be a marker for stem cells in the hair follicles (Lyle et al, 1998). To try and understand the function of K15, we have used monoclonal and polyclonal antibodies to examine the distribution of K15 in normal and pathological tissue and in keratinocytes grown under various culture conditions. Our results point toward a distinct expression range for $\mathrm{K} 15$, which suggests that the two basal cell keratins may have quite different functions.

\section{Results}

Two new antibodies specific for human K15 were used in this study. The first is an anti-C-terminal peptide polyclonal antibody to K15, IMP15, which enabled double immunofluorescence to be carried out, and the second is a monoclonal antibody, LC18N, which arose fortuitously. These antibodies were used in addition to monoclonal antibody LHK15 (Waseem et al, 1999) to give greater confidence in interpreting immunohistochemistry results. In immunoblots of protein extracted from human epidermis, IMP15 recognizes a band at $50 \mathrm{kDa}$ compared with a $48 \mathrm{kDa}$ band in mouse extracts (Fig. 1a). This difference in mobility between human and mouse $\mathrm{K} 15$ has been observed previously with a polyclonal antibody raised to a similar peptide (Lloyd et al, 1995).

The monoclonal antibody LC18N was raised against human $\mathrm{K} 18$, but was found to also recognize a protein in the basal layer of human epidermis where K18 is not expressed. Immunoblotting analysis identified a single protein species with a mobility comparable to the basal keratinocyte keratins K14 or K15. To determine which keratin was the target for this antibody, extracts of the HaCaT keratinocyte cell line were prepared after 3 and 9 days of culture, because previous studies had indicated that K15 was only expressed in confluent cultures (Ryle et al, 1989). The LC18N-reactive 50 kDa band was only observed in blots of HaCaT cells after 9 days of culture, suggesting that human $\mathrm{K} 15$, and not $\mathrm{K} 14$, was the target of this antibody (Fig. 1a). LC18N is not immunoreactive with mouse K15.

To further test the monospecificity of the antibodies to $\mathrm{K} 15$, PtK2 cells were transfected with various human keratin cDNAs including $\mathrm{K} 14$ and $\mathrm{K} 15$ (see also below). Immunoblotting of keratin extracts from these cells clearly indicated that IMP-15 bound to K15 and not K14 (Fig. 1b). LC18N was unable to detect the level of K15 present in these extracts, but immunocytochemistry indicated that only transfections with K15 CDNA gave rise to staining with LC18N (Fig. 2). (LC18N does not react with PtK2 [potoroo] K18.)

Because LC18N was raised to an $\mathrm{N}$-terminal peptide of $\mathrm{K} 18$, it was assumed that it bound to a different epitope from the IMP15 target. To confirm this, glutathione S-transferase (GST) fusion proteins with either the head or tail domains of human K15 were produced in bacteria. Western blotting showed that IMP15 and

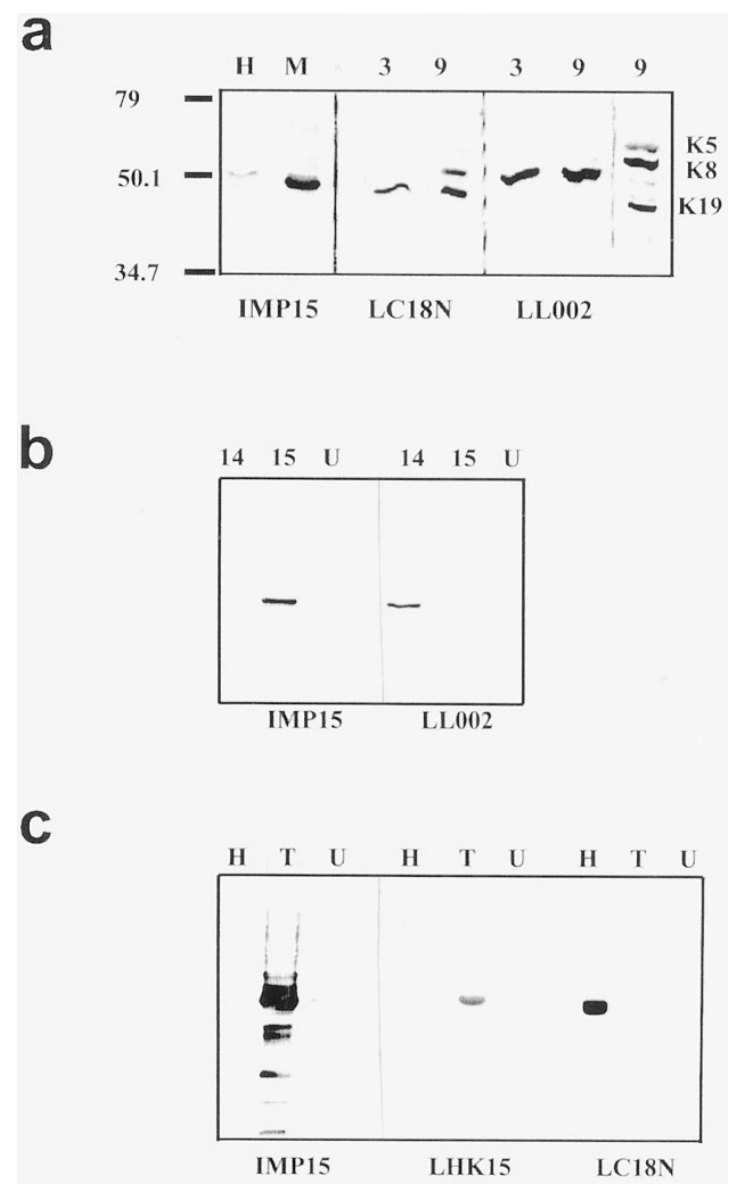

Figure 1.

Characterization of K15 antibodies by immunoblotting. $a$, Lysates of epidermis and keratinocytes on an $8.5 \%$ polyacrylamide gel. IMP15 recognizes a $50 \mathrm{kDa}$ band in human epidermis $(\mathrm{H})$ compared with a $48-\mathrm{kDa}$ band in mouse epidermis (M). HaCaT cell lysate after 3 or 9 days of culture were immunoblotted with antibodies LC18N (to K18 and K15), and LL002 (to K14). LC18N detects 2 bands: the lower band is K18 and the upper band K15; LL002 confirms that $\mathrm{K} 14$ is constitutively expressed in $\mathrm{HaCaT}$ cells. The mobility of prestained molecular weight markers (BioRad, Richmond, California) is indicated in kilodaltons on the left-hand side. The relative mobility of other keratins detected with RCK102/LP2K in lysate from HaCaT cultured for 9 days is also shown for comparison. $b, 10 \%$ polyacrylamide gel of lysates from PtK2 cells transfected with K14, K15, CDNA, or from untransfected PtK2 (U) probed with IMP15 or LL002. c, 15\% polyacrylamide gel of GST fusion proteins. Lysates of bacteria transfected with pGEX vectors expressing the K15 head $(\mathrm{H})$ or tail (T) GST fusion proteins, (U) untransfected bacterial lysate control. LC18N detected only the head fusion protein and LHK15/IMP15 detected the tail fusion protein. 

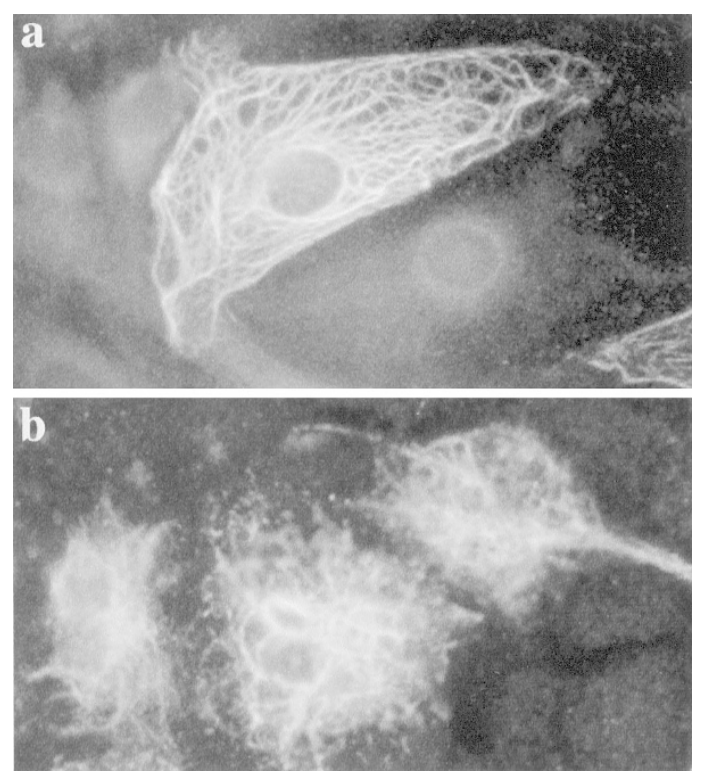

Figure 2.

Filament-forming ability of K15. a, PtK2 cells were transfected with keratin 15 cDNA and stained with $\mathrm{LC} 18 \mathrm{~N}$ to show integration of $\mathrm{K} 15$ into the pre-existing K8/K18 filaments. No staining was observed in untransfected cells. $b$, Keratin 15 CDNA cotransfected with K5 CDNA into keratin-free H36/CEl lens cells and stained with LHK15 shows that K15 can form filaments de novo.

LHK15 bound to the tail domain as expected and LC18N bound to the head domain (Fig. 1c).

Throughout this study, keratin 14 was monitored using well-characterized monoclonal antibodies to the
C-terminal peptide of K14 (LL002; Purkis et al, 1990), the analogous region to that used to raise the LHK15 and IMP15 antibodies. The immunohistochemical results of this study, discussed below, are summarized in Table 1.

\section{K15 Expression in Normal Human Epithelia}

In human stratified squamous epithelia, all three K15 antibodies gave the same staining patterns. In frozen unfixed sections, K15 expression was completely restricted to the basal layer of epidermis in the sites examined (thigh, axilla, breast, and scalp), whereas K14 protein was also detectable in suprabasal layers (Fig. 3, a to c). All basal cells were positive for K14 but some cells were K15 negative; these cells occurred in patches but did not show any specific location in the epidermis. Buccal and palate mucosa were similar to normal epidermis, with basally restricted K15 expression (Fig. 3d). These epithelia also constitutively express $\mathrm{K} 6$ and $\mathrm{K} 16$. In plantar epidermis (Fig. 3, e and f), K15 was expressed at much lower levels than in interfollicular epidermis. Only isolated K15-positive groups or single cells were observed, usually deep in the epidermal ridges of the foot sole (double immunofluorescence with antibodies to K19 excluded the possibility that these were Merkel cells). Sweat glands showed reciprocal differences in K14 and K15 antibody reactivity, as myoepithelial cells were $\mathrm{K} 14$ positive, K15-negative, whereas the luminal cells were K14-negative, K15-positive (Fig. 3, g and h).

Table 1. K15 Expression in Epithelial Tissues as Determined by Immunohistochemistry

\begin{tabular}{|c|c|c|}
\hline Body site & K15 staining & K14 staining \\
\hline \multicolumn{3}{|l|}{ Human tissues } \\
\hline \multicolumn{3}{|l|}{ Thin, hair-bearing } \\
\hline Thigh & Basal layer cells, some negative patches & Basal and suprabasal layer cells \\
\hline \multicolumn{3}{|c|}{ 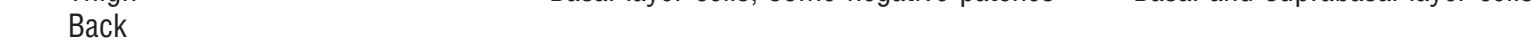 } \\
\hline \multicolumn{3}{|l|}{ Breast } \\
\hline \multicolumn{3}{|l|}{ Scalp } \\
\hline \multicolumn{3}{|l|}{ Axilla } \\
\hline Hair follicles & Basal cells in outer root sheath & Outer root sheath, all cells \\
\hline Sweat glands & Luminal cells & Myoepithelial cells \\
\hline \multicolumn{3}{|l|}{ Mucosal } \\
\hline Buccal epithelium & Basal layer & Basal and suprabasal layer cells \\
\hline Palate & Basal layer & \\
\hline \multicolumn{3}{|l|}{ Thick, glabrous } \\
\hline Plantar epidermis & Few basal cells & All basal and suprabasal cells \\
\hline \multicolumn{3}{|l|}{ Pathological } \\
\hline Wound healing (suction blister) & Decreased 48 hour after wounding & Unchanged: all cells \\
\hline Psoriasis (lesion) & Basal cells & Basal and suprabasal cells \\
\hline Basal cell carcinoma & Positive; variable intensity & All cells stained \\
\hline $\begin{array}{l}\text { Basal cell carcinoma overlying } \\
\text { epidermis }\end{array}$ & Basal cell expression, decreased in some & Unaltered \\
\hline Squamous cell carcinoma (in situ) & Mostly negative & All cells positive \\
\hline \multicolumn{3}{|l|}{ Mouse tissues } \\
\hline Esophagus: neonatal & Basal and suprabasal & All cells \\
\hline Esophagus: adult & Basal cells only & All cells \\
\hline \multicolumn{3}{|l|}{ Tissue culture } \\
\hline HaCaT in DMEM & Increased at confluence & Constitutive in all cells \\
\hline $\mathrm{HaCaT}$ in KGM & Not increased at confluence & Constitutive in all cells \\
\hline
\end{tabular}


In hair follicles K15 was expressed in the basal layer of the outer root sheath (Fig. 3, g and h) except in the isthmus region (Fig. 4), between the sebaceous gland duct and the bulge, where the keratinocytes are very flattened and attenuated. This region may correspond to the K15-negative area detected in sheep hair follicles by Whitbread and Powell (1998).

\section{K15 Expression in Stressed and Pathological Human Epidermis}

During wound healing, keratinocytes at the wound edge undergo cell shape changes and become migratory (Gabbiani et al, 1978; Paladini et al, 1996) and changes in keratin expression take place (Mansbridge and Knapp, 1987). Suction blister (epidermal) wounds were therefore examined for changes in K15 expression, using LHK15 to monitor K15 expression at various time points up to 96 hours after injury. Before keratinocyte migration (time points up to 24 hours), normal levels of K15 were detected in all basal cells. By 48 hours, as the tongue of migrating keratinocytes advanced over the denuded dermis, K15 was only seen in some of the basal cells (Fig. 5a). By 96 hours, K15 expression was completely lost from the leading edge, blister roof, and the wound margin (Fig. 5c). Antibodies to $\mathrm{K} 16$ at this time showed suprabasal
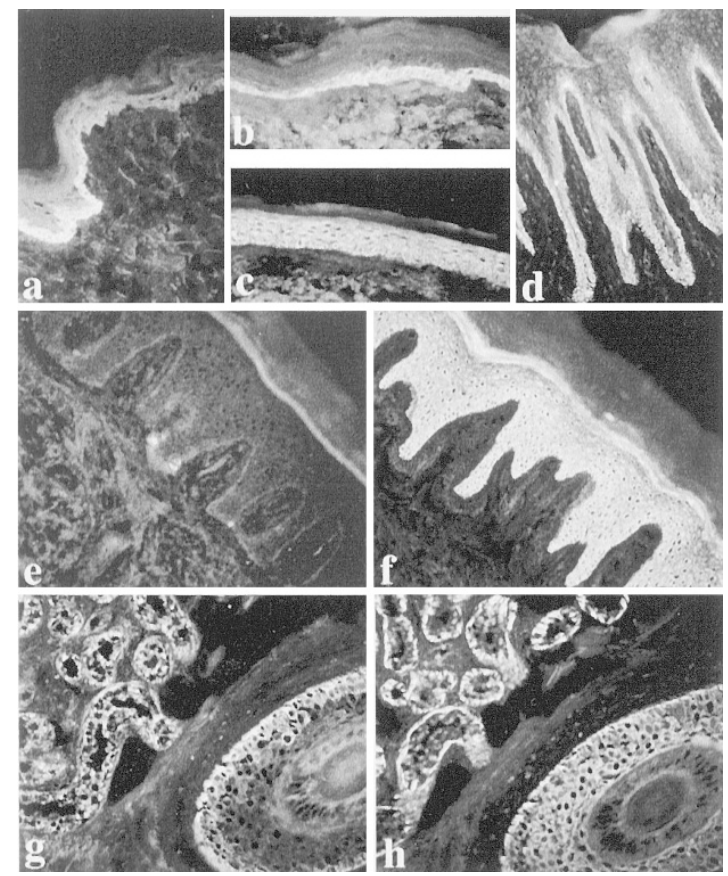

Figure 3.

K15 expression in normal adult human epithelia, shown by immunofluorescence on frozen methanol-acetone-fixed sections. a, K15 expression in face skin with some keratin-positive and negative regions. $b$, In interfollicular scalp epidermis, $\mathrm{K} 15$ is basal in location but $\mathrm{K} 14(c)$ is expressed throughout all layers. $d$, Basal expression of $\mathrm{K} 15$ was also observed in the palate. $e$, In plantar epidermis very few K15 positive cells are observed, whereas K14 $(f)$ is expressed in all layers. $g$ and $h$, In epidermal appendages $\mathrm{K} 15(g)$ is observed in the basal cells of the outer root sheath of hair follicles and in the luminal cells of the secretory sweat gland; in contrast, $\mathrm{K} 14(h)$ is seen throughout the outer root sheath and in the myoepithelial cells of sweat gland.

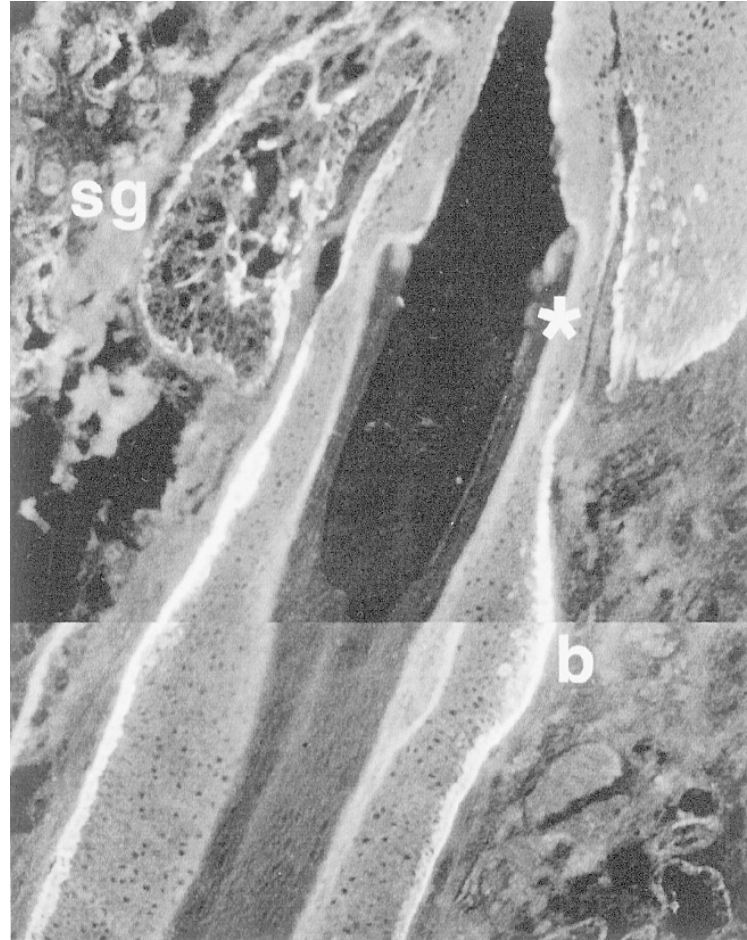

Figure 4.

K15-negative region in the outer root sheath of hair follicles. Two overlapping photographs of a scalp hair follicle stained with LHK15. A region negative for K15 can be observed above the bulge $(b)$, at the isthmus $\left({ }^{*}\right)$. Sebaceous gland $(s g)$

staining of the new epithelium and surrounding wound margins (Fig. 5d). K15 has also recently been reported to be reduced during re-epithelialization of fullthickness mouse wounds (Werner et al, 2000).

Psoriatic epidermis is often cited as showing an expanded basal compartment, although keratin expression data has not supported this (Leigh et al, 1985). In samples from six psoriatic lesions, K15 was detected, by all three antibodies, in many but not all of the basal cells (Fig. 6, g and h), but not in any suprabasal cells. These same regions of the epidermis show strong up-regulation of keratins 6 and 16 (Weiss et al, 1984; Wilson et al, 1994).

Nonmelanoma skin cancers were also assayed for K15 expression. A total of 11 basal cell carcinomas examined were positive for both $\mathrm{K} 15$ and $\mathrm{K} 14$, expressed in the peripheral basal layer and in cells throughout the body of the tumor, although the intensity of K15 staining varied from cell to cell (Fig. 6a). In the epidermis overlying the tumours, $\mathrm{K} 15$ was usually still present in the basal layer (only) but in 4 of the samples examined the number of K15-positive basal cells was very low (Fig. 6d). In contrast, K14 was expressed throughout the living layers of the overlying epidermis (Fig. 6c).

In 7 of 10 squamous cell carcinoma samples, tumours were completely negative for $\mathrm{K} 15$. In squamous cell carcinomas where $\mathrm{K} 15$ was detected, less than $10 \%$ of cells were positive (Fig. 6e) or the positive staining was restricted to a sector of the tumor. Again, 

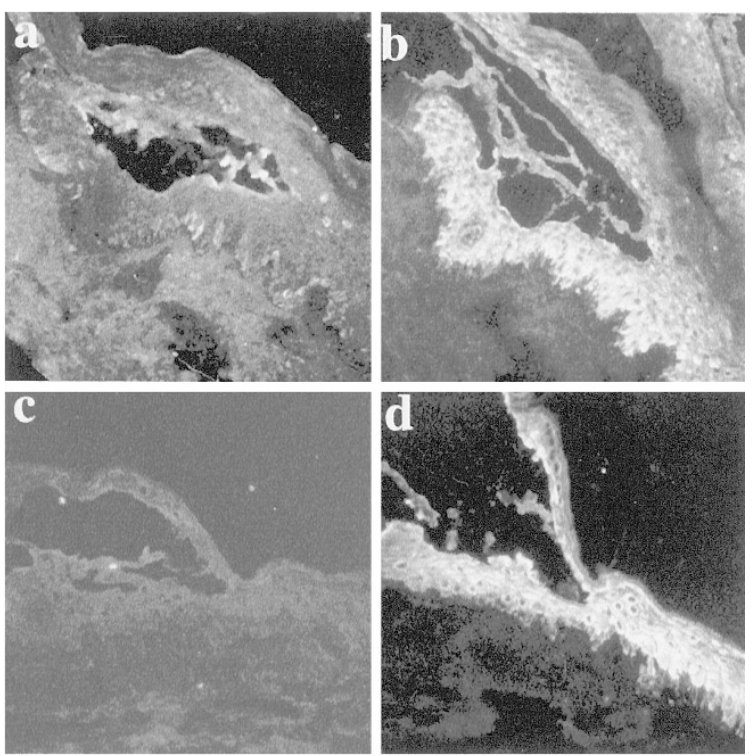

\section{Figure 5 .}

K15 expression changes in wound healing, shown by immunofluorescence on frozen methanol-acetone-fixed sections. Epidermal suction blister wounds show low levels of K15 expression in some basal cells (a) 48 hours after blister formation and in the regenerating leading edge of keratinocytes migrating over the stripped dermis. $c$, No K15 is seen in the blister roof or surrounding wound margin at 96 hours after formation. At 48 hours $(b)$ and 96 hours $(d)$ after wounding, K6 (b) and K16 (d) are both extensively expressed in suprabasal cells of the re-epithelializing leading edge and wound margin.

K14 staining was observed in all these tumor cells (Fig. 6f). LC18N was not used for this part of the study because it is known that nonmelanoma skin cancers can sometimes express K18 (Markey et al, 1992).

\section{K15 Expression in Relation to the Proliferation Marker Ki67}

The basal location of $\mathrm{K} 15$ cells suggested a possible link with proliferative potential since most dividing cells are found in this layer of the epidermis. Ki67 is a cell proliferation marker that is expressed in all phases of the cell cycle except G0 (Sasaki et al, 1987; Scott et al, 1991) and so we examined its expression relative to that of K15. A greatly enhanced number of Ki67positive cells were observed in the basal and epibasal cells of the psoriatic samples. The majority of Ki67positive cells were also positive for $\mathrm{K} 15$, but in both normal epidermis and epidermis from psoriatic lesions, some suprabasal Ki67-positive cells were K15negative (Fig. 7). Large numbers of Ki67-positive cells were observed in the plantar epidermis, which shows very few K15-positive cells (Fig. 3e). Thus there appears to be no correlation between K15 expression and cell proliferation.

\section{Suprabasal Expression of K15}

Expression of K15 in suprabasal cells is unusual and to date has been reported only in the esophagus (Leube et al, 1988; Lloyd et al, 1995). In agreement with Lloyd et al (1995) we observed expression of K15 throughout the basal and suprabasal layers of neonatal mouse esophagus, but in the adult mouse K15 expression was restricted to the basal layer (Fig. 8, a and b). This would account for the progressive reduction in the protein ratio of K15: K14 which was reported to occur with age in mouse esophagus (Lloyd et al, 1995). In adult sheep, K15 is also confined to the
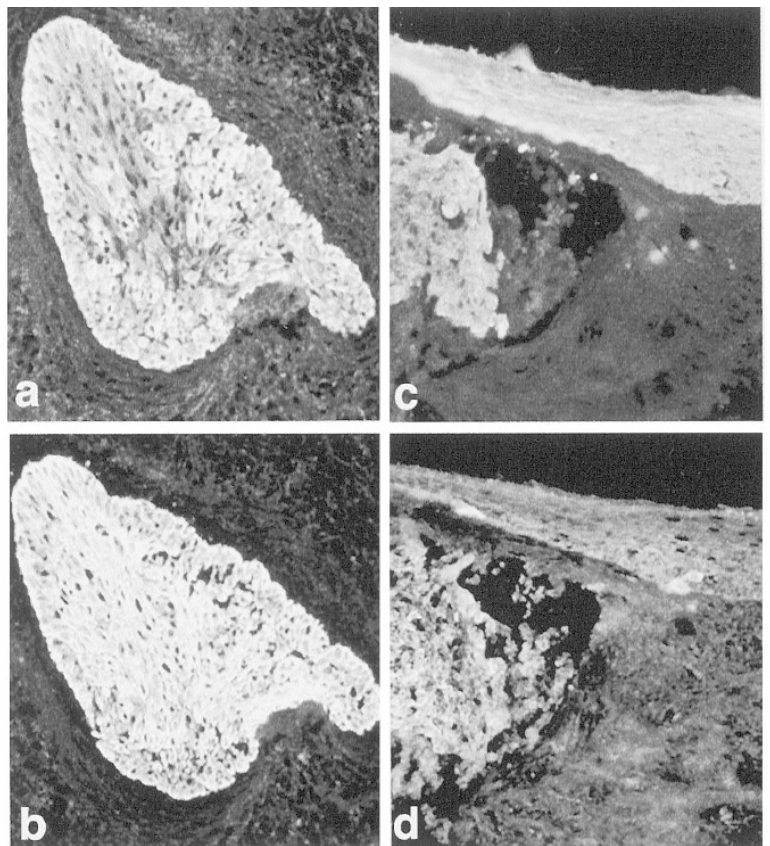
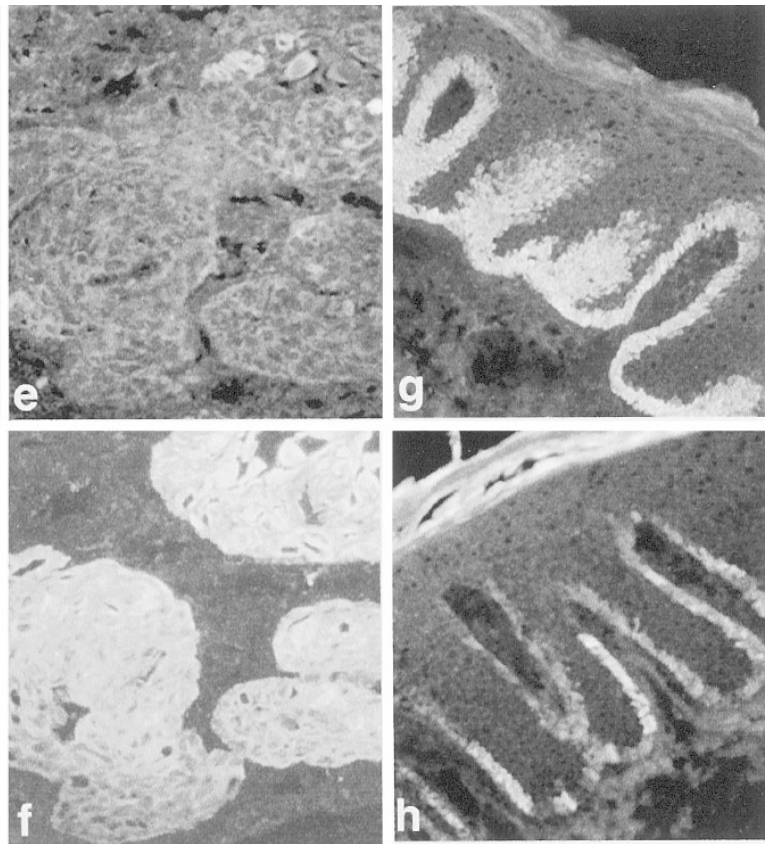

Figure 6.

Keratin 15 expression in disease. Some basal cell carcinomas show heterogeneous staining with LHK15 (a) and homogeneous K14 staining with LL002 (b). Very few basal cells were K15 positive in the epidermis overlying basal cell carcinomas (d), whereas K14 was expressed in all layers (c). Those squamous cell carcinomas that were positive for K15 had only a few positive cells (e) but, as with basal cell carcinomas, all cells were K14 positive ( $f$ ). In psoriatic plaques K15 was located in many but not necessarily all basal cells ( $g$ and $h)$. 

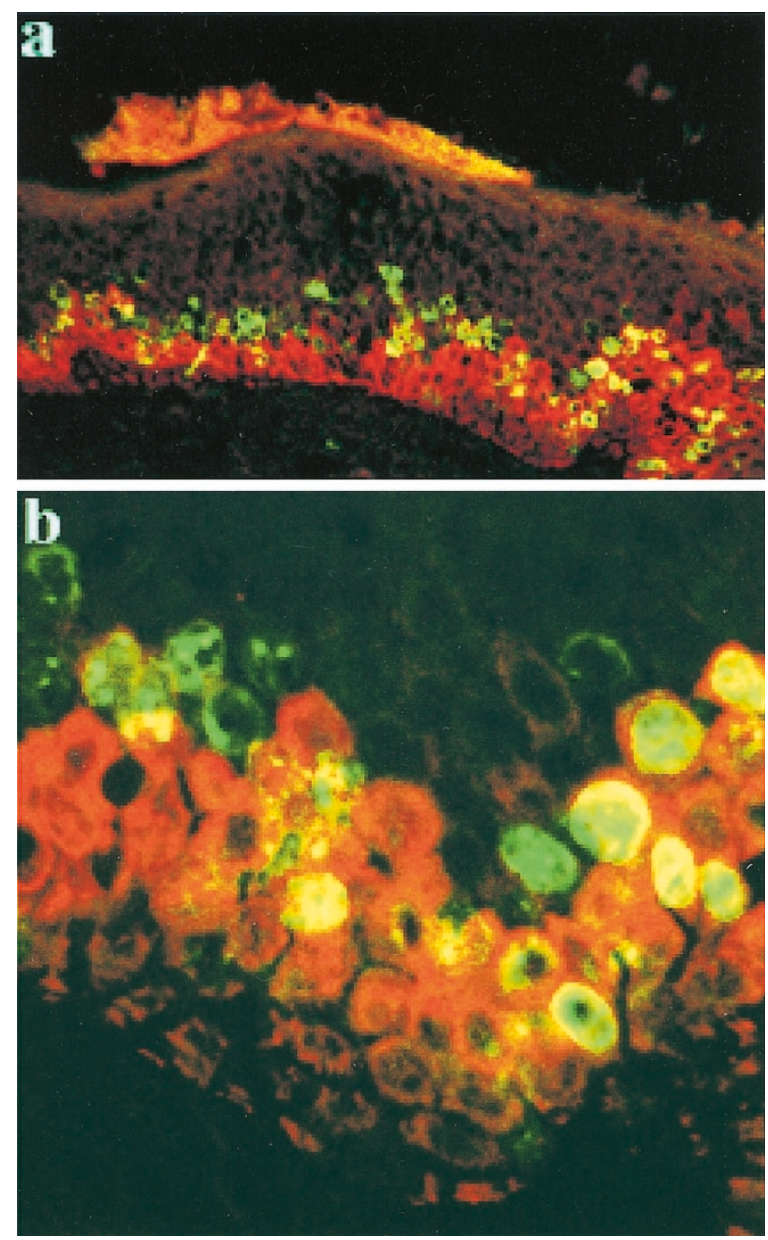

Figure 7.

K15 expression is not tightly coupled to proliferation in the epidermis. Double labeling of K15 and the proliferation marker Ki67 in frozen methanol-acetonefixed sections of interfollicular scalp epidermis. a, Ki67 (green Alexa dye) and K15 (red Alexa dye). Note that some K15-negative cells are Ki67 positive. $b$, Higher magnification of a region in panel $a$.

basal layer of the esophagus (Whitbread and Powell, 1998). K15 has been reported to be expressed throughout the adult human esophagus based on in situ hybridization (Leube et al, 1988), but more recently it was shown with antibody LHK15 that K15 protein is also confined to the basal layer in human esophagus (Waseem et al, 1999).
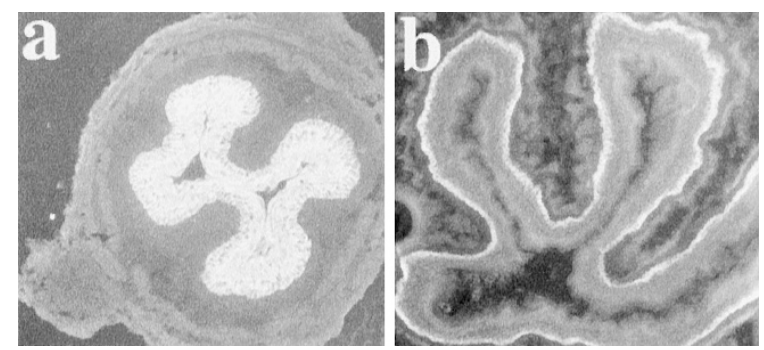

Figure 8.

Suprabasal expression of $\mathrm{K} 15$, seen by immunofluorescence on frozen methanol-acetone-fixed sections. K15 is expressed in the basal and suprabasal epidermis of neonatal mouse esophagus (a) but is restricted to the basal layer of adult mouse esophagus $(b)$.

\section{K15 Filament Assembly}

A rare recessive form of the skin fragility disorder epidermolysis bullosa simplex (EBS) exists in which K14 is totally lacking (Chan et al, 1994; Jonkman et al, 1996; Rugg et al, 1994). The absence of an extensive intermediate filament network in epidermal basal cells of such patients, and of transgenic mice (Lloyd et al, 1995), suggested that K15 cannot compensate for the lack of K14. We therefore carried out transfection experiments to study the filament-forming ability of K15. Transfections were carried out in PtK2 cells with either $\mathrm{K} 15$ or $\mathrm{K} 14 \mathrm{cDNA}$ in the mammalian expression vector pcDNA3. K15 integrated into the endogenous $\mathrm{K} 8 / \mathrm{K} 18$ filament network with similar efficiency to K14, showing no irregularity in the keratin filaments (Fig. 2a). Transfections into the lens cell line H36/CEI showed that $\mathrm{K} 15$ could form de novo filaments comparable to K14 with the basal cell type II keratin K5 (Fig. 2b) (Porter et al, 1998).

\section{K15 Expression in Stratified and Nonstratified Keratinocyte Cultures}

Cells of the human keratinocyte $\mathrm{HaCaT}$ line have been reported to express $\mathrm{K} 15$ at very low levels until the cells become confluent (Ryle et al, 1989). The suggestion was made that this expression correlated with the onset of stratification. To test this possibility $\mathrm{HaCaT}$ cells were grown in the presence and absence of calcium, which is known to affect the stratification of keratinocytes in culture (Pillai et al, 1990). These experiments were carried out in either Dulbecco's modified Eagle's medium (DMEM) with 10\% fetal calf serum or in serum-free keratinocyte growth medium (KGM). HaCaT cells grown in the absence of calcium appeared more rounded in morphology than those grown with calcium (Fig. 9, a and b), but only slight differences were observed between cells grown in the two media. As previously observed, both E-cadherin (not shown) and desmoplakin (Fig. 9e) remained cytoplasmic in cells grown without calcium, indicating poor formation of adherens junctions and desmosomes (Jones and Goldman, 1985; O'Keefe et al, 1987; Watt et al, 1984). HaCaT cells grown in $1 \mathrm{~mm}$ calcium showed the expected membrane distribution for both E-cadherin and desmoplakin and formed well spread flattened keratinocytes (Fig. 9f).

The formation of junctions appeared similar in both DMEM and in serum-free KGM. However K15 expression was different. In DMEM, with or without calcium, K15 was expressed only at low levels until confluence (Fig. 9g), whereupon K15 levels increased. In contrast, HaCaT cells grown in KGM (serum-free medium) expressed K15 in sparse cultures but expression levels stayed constant, or even decreased, with time after plating (Fig. 9g). Again, the presence or absence of calcium did not alter K15 expression. The difference between the two culture media probably reflects the presence of epidermal growth factor in the KGM medium, as EGF has recently been shown to suppress K15 expression (Werner et al, 2000). 


\section{Discussion}

The basal cell compartment of stratified squamous epithelia has a clearly defined function in harboring the proliferative cells of the tissue. The best-defined function of keratin intermediate filaments is their role in determining the physical resilience that cells need to survive in a particular tissue location. With this project we set ourselves the aim of discovering the function of a keratin within the proliferative zone of stratified epithelia.
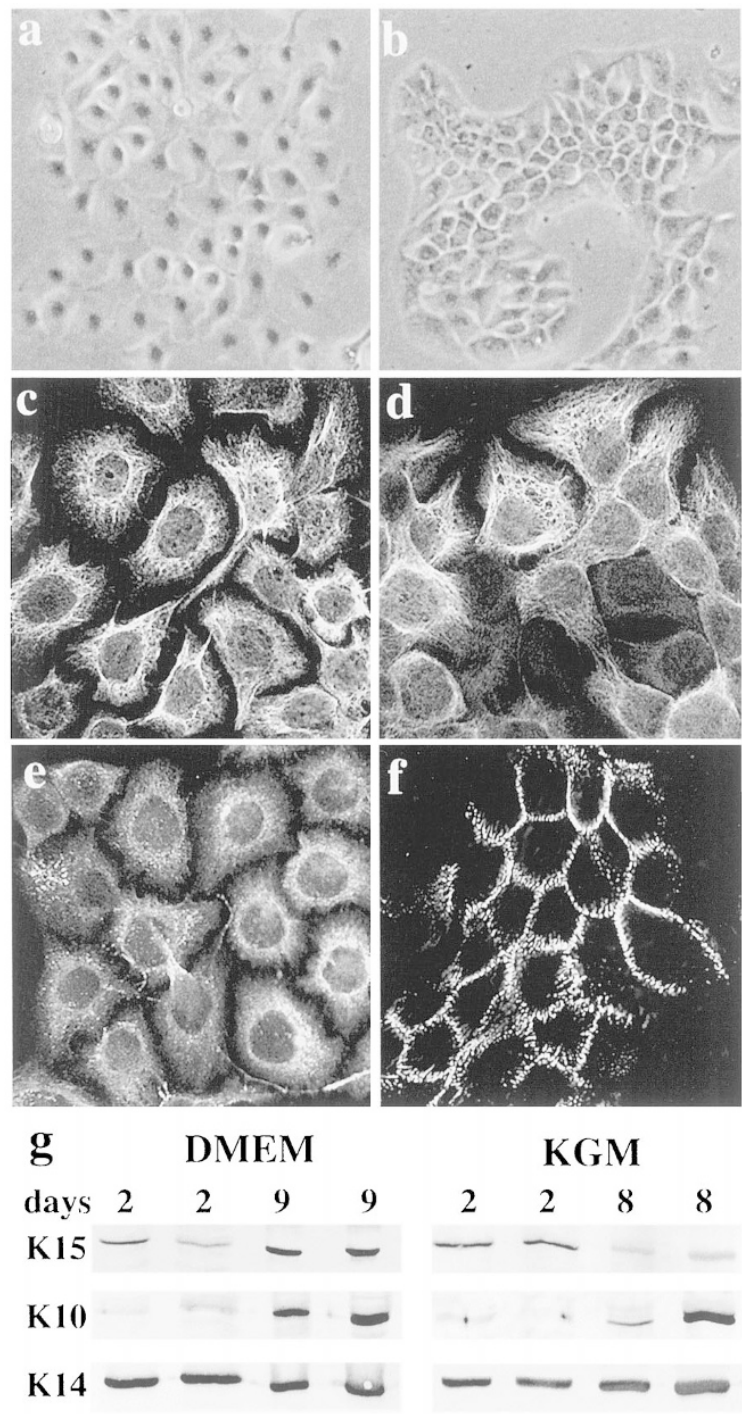

$(\mathrm{a} 2+0 \mathrm{mM} \quad \mathrm{mM} \quad 0 \mathrm{mM} \quad 1 \mathrm{mM}$

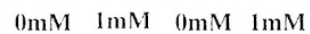

\section{Figure 9.}

The effect of calcium on $\mathrm{K} 15$ expression in $\mathrm{HaCaT}$ cultures. HaCaT cells grown in KGM for 2 days, either without calcium ( $a, c$, and $e$ ) or with $1 \mathrm{~mm}$ calcium $(b, d$, and $f$ ) in the medium. $a$ and $b$, Phase contrast; $c$ and $d, \mathrm{~K} 15$ staining with antibody LHK15; $e$ and $f$, desmosome staining with antidesmoplakin antibody 11-F5. The cells grow in a more compact form with calcium; K15 filaments look the same but desmosomes are properly formed only in the presence of calcium. $g$, Western blots of tissue extracts from HaCaT cells grown at 0 or 1 mM calcium in KGM or DMEM for 2 or 8/9 days, stained with LHK15 (K15), LL002 (K14), or LH2 (K10). Calcium increases the amount of K10 expressed after a week but has no effect on the amount of K15 expressed. Culture in DMEM (but not serum-free KGM) for 9 days increases K15 expression.
Although $\mathrm{K} 15$ is primarily expressed in the basal proliferative layer, several lines of investigation show that there is no close correlation between proliferation and K15 expression. Highly proliferative tissues (plantar epidermis, wound edge epidermis, squamous cell carcinoma) show a reduction in K15. Neither can the suggestion (Lyle et al, 1998) that K15 is a marker for stem cells in the hair follicle be strictly correct. When we compared the CD8/144B antibody used by Lyle and colleagues with known K15-specific antibodies, we observed that (i) CD8/144B gave a substantial underestimation of the number of $\mathrm{K} 15$ cells in skin when compared with LHK15, IMP15, or LC18N, and there are far too many $\mathrm{K} 15$-positive cells for them all to be stem cells; and (ii) CD8/144B failed to react with K15-transfected cells in circumstances in which the other antibodies gave a clear strong reaction. We must conclude that either CD8/144B reacts with a different target antigen, or that its cross-reaction with $\mathrm{K} 15$ is weak. This does not however exclude the possibility that some of the K15-positive cells are stem cells.

A more relevant feature of stem cells however may be their differential adhesion to the basal lamina. Jones et al (1995) have shown that stem cell-enriched populations of basal keratinocytes express higher levels of integrins on their surface, presumably to hold the long-lived slow-cycling stem cells in their epidermal niche without the risk of premature shedding. The converse of this is that non-stem cells are more likely to shift position in the epidermis. This may be upward, as in terminal differentiation, or it may be horizontally along the basal lamina to repopulate non-stem cell bearing regions of the epidermis. These movements would clearly be required where stem cell niches occur in structurally defined positions, such as at the base of deep epidermal rete pegs or in the hair follicle bulge region or, out with the epidermis in the tongue's filiform papillae, or corneal limbus pockets of stem cells (Cotsarelis et al, 1989).

Thus epidermal differentiation must take place both laterally and vertically. Vertical differentiation involves the process of progressive terminal differentiation from basal cells to stratum corneum. Our results suggest that $\mathrm{K} 15$ expression is not linked to this vertical differentiation. A second type of differentiation must take place along the basal lamina following the movement of cells away from the stem cell pockets. We propose that the expression of $\mathrm{K} 15$ may be an indicator of this lateral differentiation, a differentiation marker within the basal cell compartment itself. Its presence may indicate a degree of maturation of basal cells that is seen in stable and slowly turning over epithelial basal cells. This is compatible with some K15-positive cells being stem cells. K15 may impart an additional physical stability to the basal cell compartment, which helps to maintain tissue architecture. This stability would probably reduce flexibility or plasticity in the tissue and may be incompatible with any more than a small degree of cell deformation and migration. Consistent with this idea, $\mathrm{K} 15$ is reduced in wound healing and in tumor metastasis. Absence of K15 may therefore be associated with cell stretching, flattening, 
migration, deformation, and even rapid growth. It may be necessary (or selected for) in cell populations undergoing morphogenetic or metastatic changes, which could account for selection of K15-negative cells during tumor progression of metastatic squamous cell carcinomas. Absence of K15 may prove to be a useful and informative prognostic indicator in skin cancers.

\section{Materials and Methods}

\section{Antibodies Used}

A polyclonal antibody to K15 (IMP15) was obtained by immunizing rabbits with the C-terminal peptide of human K15, DGQVVSSHKREI, linked to keyhole limpet hemocyanin. The monoclonal antibody LC18N was raised to the $\mathrm{N}$-terminal peptide of human $\mathrm{K} 18$, SFTTRSTFS, but was subsequently found to crossreact with human $\mathrm{K} 15$.

Another antibody recently reported to cross-react with K15, C8/144B (Lyle et al, 1998) (DAKO), was also tested but because it was found to be unreactive on K15-transfected cell cultures it was not used further in this study. Other keratin antibodies were LE41 (K8) and LE61 (K18) (Lane, 1982), LL002 (K14) (Purkis et al, 1990), LL025 (K16) (Wilson et al, 1994), LHK6 (K6) and LHK15 (K15) (Waseem et al, 1999), LP2K (K19) (Stasiak et al, 1989) RCK102 (K5 \&K8) (Broers et al, 1986), and LH2 (K10) (Leigh et al, 1993). Additional monoclonal antibodies used were E-cadherin (Transduction Laboratories, Lexington, Kentucky) diluted 1:50, 11-5F (anti-desmoplakin) (Parrish et al, 1987) diluted 1:100; and MM-1 (anti-Ki67) (Novacastra, Newcastle upon Tyne, United Kingdom).

\section{Immunohistochemistry}

Samples of normal skin were obtained from cosmetic surgical procedures. Specimens of psoriatic lesions (n $=6$ ) were obtained by punch biopsy, and basal cell carcinoma $(n=11)$ and squamous cell carcinoma samples $(n=10)$ were obtained by surgical resection and snap frozen in OCT. Specimens of mouse esophagus were taken from CD-1 mice. Frozen sections were fixed in methanol: acetone $1: 1$ at $-20^{\circ} \mathrm{C}$ for 5 minutes and incubated with IMP15 diluted 1:200 in phosphate buffered saline pH7.5 or LC18N undiluted for 1 hour at room temperature. Other antibodies were diluted as described in the references above. The secondary antibodies were FITC conjugated goat antirabbit IgGs or anti-mouse IgGs (Sigma, Poole, United Kingdom) for single labeling, or Alexa dye conjugated affinity purified antibodies (Molecular Probes, Leiden, The Netherlands) for double labeling. Slides were mounted in Hydromount (National Diagnostics, Atlanta, Georgia) containing 2.5\% DABCO (Sigma) or Citifluor (Agar, Stansted, United Kingdom).

\section{Cell Culture}

HaCaT cells were plated in DMEM with $10 \%$ FCS and grown for 3 or 9 days. Medium was changed every 2-3 days. For stratification studies HaCaT cells were plated in $\mathrm{Ca}^{2+}$ free DMEM (Life Sciences, Paisley, United Kingdom) with 10\% FCS treated with Chelex 100 resin (Sigma) with or without $1 \mathrm{mM} \mathrm{Ca}^{2+}$. In other experiments cells were plated in DMEM for 24 hours then grown in serum-free Clonetic's keratinocyte growth medium (KGM; Biowhittaker, Wokingham, United Kingdom), with or without $1 \mathrm{mM} \mathrm{Ca}^{2+}$. PtK2 cells for transfection were cultured in 50:50 Ham's F12 and DMEM with 10\% FCS added. For immunofluorescence studies, cells were plated on 13-mm diameter glass coverslips.

\section{Transfection of Cultured Cells}

Human K15 cDNA was amplified using PCR in standard buffer containing $1.5 \mathrm{~mm}$ magnesium chloride. The forward and reverse primers used were: 5'-AACTCACGGGCTCCAGCTAC-3' and 5'-GAATAGAGCGCATGCAAAGC-3', respectively. Thirty-five cycles were run consisting of denaturation at $94^{\circ} \mathrm{C}$ (30 seconds), annealing at $60^{\circ} \mathrm{C}$ ( 1 minute), and synthesis at $72^{\circ} \mathrm{C}$ for 2 minutes. The PCR product was then cloned into pGEM (Promega, Southampton, United Kingdom), sequenced, and then subcloned into the expression vector pcDNA3 (Invitrogen, Leek, The Netherlands). One to two micrograms of human $\mathrm{K} 14$ or $\mathrm{K} 15$ cDNA in pcDNA3 were transfected into subconfluent PtK2 cells using FuGENE reagent (Boehringer-Mannheim, Lewes, United Kingdom). At 48 hours after transfection the cells were fixed for 1 minute at $-20^{\circ} \mathrm{C}$ in methanol/acetone 1:1. Staining was carried out as described for frozen sections. Cotransfections of K5/K15 cDNA in pcDNA3 into H36/CEI cells were as described previously (Porter et al, 1998).

\section{GST Fusion Protein Preparation}

The cDNA encoding the head domain of human K15 was generated by PCR of the pcDNA3 K15 vector using a forward primer including a $\mathrm{BamHI}$ restriction site at the beginning of the $\mathrm{K} 15$ head sequence: GGATCCACCACCACATTTCTGCAAACT; and a reverse primer CTCATTGCCAGAGAGGAGACC (beginning at bp 376 of hK15 accession no: $\times 07696)$. The cDNA encoding the tail domain was generated by PCR using a forward primer starting at bp 1301, again with a BamHI site at the start: GGATCCGATGCCAAGATGGCTGGCATTG and a reverse primer starting at the TAA stop codon (bp1432) TTAGATTTCTCTCTTGTGGG. Amplification with Taq polymerase (Applied Biosystems, Warrington, United Kingdom) was carried out in buffer contained $1.5 \mathrm{~mm} \mathrm{Mg}^{2+}$ under the following conditions: denaturing at $94^{\circ} \mathrm{C}$ for 30 seconds, annealing at $55^{\circ} \mathrm{C}$ for 30 seconds, and synthesis at $72^{\circ} \mathrm{C}$ for 45 seconds. The products were cloned into pGEM (Promega) and then subcloned into pGEX-2 (Amersham Pharmacia Biotech, Little Chalfont, United Kingdom) using $\mathrm{Bam} \mathrm{HI}$ and $\mathrm{EcoRI}$ restriction sites. Escherichia coli strain BL21 (DE3) pLysS were transformed with the pGEX vectors and grown in $2 X \mathrm{YT}$ broth $(2 \mathrm{ml})$ to OD600 $=0.8$ before inducing protein expression with isopropyl- $\beta$-D-thiogalactopyranoside 
$(0.5 \mathrm{~mm})$ for 2 hours. Bacteria were pelleted and boiled for 5 minutes in SDS-sample buffer. Western blotting was carried out as described below.

\section{SDS-PAGE and Western Analysis}

Cultured cells or skin tissue were boiled in SDS-PAGE sample buffer for 5 minutes. For PtK2 transfection experiments, keratin-enriched fractions were prepared by extraction in $10 \mathrm{~mm}$ Tris- $\mathrm{HCl}$ containing $5 \mathrm{~mm}$ ethylenediaminetetraacetic acid, 140 mm sodium chloride, $0.5 \%$ Nonidet $\mathrm{P}-40$, and complete enzyme inhibitor (Boehringer-Mannheim, Mannheim, Germany) on ice for 20 minutes. The keratin-enriched fraction was obtained by sedimentation of insoluble material at $14000 \mathrm{rpm}$ at $4^{\circ} \mathrm{C}$ for 20 minutes. SDS-PAGE and blotting were carried out as previously described. Primary antibodies were diluted as follows: IMP15 1:1000, LC18N undiluted, LL002 1:100, LHK15 1:10, LP2K and RCK102 1:1 in Tris buffered saline/0.1\% TWEEN 20. Secondary antibodies were antimouse or antirabbit immunoglobulins conjugated to horse radish peroxidase diluted 1:1000 (DAKO, Bucks, United Kingdom). Detection was with peroxidase substrate kit (Vector Laboratories, Burlingame, California).

\section{Acknowledgements}

We would like to acknowledge the contributions of Anna Keating and Andrew Freeman in pilot studies that led to this project. We thank Irene Leigh for the gift of the LHK15 antibody, David Garrod for 11-F5, Mette Mogensen for help in preparing the confocal images, Neil Wilson for sequencing work, Norbert Fusenig for $\mathrm{HaCaT}$ cells, and Roy Quinlan for useful discussions. Thanks also to the theater staff in Plastic Surgery at Ninewells Hospital, Dundee, for help in obtaining samples. Supported by the Cancer Research Campaign (SP2060/0102 to EBL) and the Wellcome Trust (Senior Basic Research Fellowship to WHIM).

\section{References}

Banks-Schlegel SP and Harris CC (1984). Aberrant Expression of Keratin Proteins and cross-linked envelopes in human esophageal carcinomas. Cancer Res 44:1153-1157.

Blobel GA, Moll R, Franke WW, and Vogt-Moykopf I (1984). Cytokeratins in normal lung and lung carcinomas. Virchows Arch B Cell Pathol 45:407-429.

Broers JLV, Carney DN, Rot MK, Schaart G, Lane EB, Vooijs GP, and Ramaekers FCS (1986). Intermediate filament proteins in classic and variant types of small cell lung carcinoma cell lines: A biochemical and immunochemical analysis using a panel of monoclonal and polyclonal antibodies. J Cell Sci 83:37-60.

Chan Y-M, Anton-Lamprecht I, Yu Q-C, Jackel A, Zabel B, Ernst J-P, and Fuchs E (1994). A human keratin 14 "knockout": The absence of K14 leads to severe epidermolysis bullosa simplex and a function for an intermediate filament protein. Genes Dev 8:2574-2587.

Collin C, Moll R, Kubicka S, Ouhayoun JP, and Franke WW (1992). Characterisation of human cytokeratin 2, an epider- mal cytoskeletal protein synthesised late during differentiation. Exp Cell Res 202:132-141.

Cotsarelis G, Cheng S-Z, Dong G, Sun T-T, and Lavker R M (1989). Existence of slow-cycling limbal epithelial basal cells that can be preferentially stimulated to proliferate: Implications on epithelial stem cells. Cell 57:201-209.

Gabbiani G, Chaponnier C, and Huttner I (1978). Cytoplasmic filaments and gap junctions in epithelial cells and myofibroblasts during wound healing. J Cell Biol 76:561-568.

Grace MP, Kim KH, True LD, and Fuchs E (1985). Keratin expression in normal esophageal epithelium and squamous cell carcinoma of the esophagus. Cancer Res 45:841-846.

Jones JCR and Goldman RD (1985). Intermediate filaments and the initiation of desmosome assembly. J Cell Biol 101: 506-517.

Jones PH, Harper S, and Watt FM (1995). Stem cell patterning and fate in human epidermis. Cell 80:83-93.

Jonkman MF, Heeres K, Pas HH, van Luyn MJA, Elema JD, Corden LD, Smith FJD, McLean WHI, Ramaekers FCS, Burton M, and Scheffer H (1996). Effects of keratin 14 ablation on the clinical and cellular phenotype in a kindred with recessive epidermolysis bullosa simplex. J Invest Dermatol 107:764-769.

Lane EB (1982). Monoclonal antibodies provide specific intramolecular markers for the study of epithelial tonofilament organization. J Cell Biol 92:665-673.

Leigh IM, Pulford KA, Ramaekers FCS, and Lane EB (1985). Psoriasis: Maintenance of an intact monolayer basal cell differentiation compartment in spite of hyperproliferation. Brit J Dermatol 113:53-64.

Leigh IM, Purkis PE, Whitehead P, and Lane EB (1993). Monospecific monoclonal antibodies to keratin 1 carboxy terminal (synthetic peptide) and to keratin 10 as markers of epidermal differentiation. Br J Dermatol 129:110-119.

Leube RE, Bader BL, Bosch FX, Zimbelmann R, Achtstaetter T, and Franke WW (1988). Molecular characterisation and expression of the stratification-related cytokeratins 4 and 15 . J Cell Biol 106:1249-1261.

Lloyd C, Yu Q-C, Cheng J, Turksen K, Degenstein L, Hutton $E$, and Fuchs $E$ (1995). The basal keratin network of stratified sqamous epithelia: Defining K15 function in the absence of K14. J Cell Biol 129:1329-1344.

Lyle S, Christofidou-Solomidou M, Liu Y, Elder DE, Albelda S, and Cotsarelis G (1998). The C8/144B monoclonal antibody recognizes cytokeratin 15 and defines the location of human hair follicle stem cells. J Cell Sci 111:3179-3188.

Mansbridge JN and Knapp AM (1987). Changes in keratinocyte maturation during wound healing. J Invest Dermatol 89:253-263.

Markey AC, Lane EB, MacDonald DM, and Leigh IM (1992). Keratin expression in basal cell carcinomas. Brit $\mathrm{J}$ Dermatol 126:154-160.

Moll R, Franke WW, Schiller DL, Geiger B, and Krepler R (1982). The catologue of human cytokeratin polypeptides: Patterns of expression of specific cytokeratins in normal epithelia, tumors and cultured cells. Cell 31:11-24.

Moll R, Levy R, Czernobilsky B, Hohlweg-Majert P, Dallenbach-Hellweg G, and Franke WW (1983). Cytokeratins of normal epithelia and some neoplasms of the female genital tract. Lab Invest 49:599-610. 
Moll R, Moll I, and Franke WW (1984). Differences of expression of cytokeratin polypeptides in various epithelial skin tumours. Arch Dermatol Res 276:349-363.

Nelson WG, and Sun T-T (1983). The 50 and 58 kdalton Keratin classes as molecular markers for stratified squamous epithelia: Cell culture studies. J Cell Biol 97:244-251.

O'Keefe EJ, Briggaman RA, and Herman B (1987). Calciuminduced assembly of adherens junctions in keratinocytes. J Cell Biol 105:807-817.

Paladini RD, Takahashi KT, Bravo NS, and Coulombe PA (1996). Onset of re-epithelialization after skin injury correlates with a reorganisation of keratin filaments in wound edge keratinocytes: Defining a potential role for keratin 16 . J Cell Biol 132:381-397.

Parrish EP, Steart PV, Garrod DR, and Weller RO (1987). Antidesmosomal monoclonal antibody in the diagnosis of intracranial tumours. J Pathol 153:265-273.

Pillai S, Bikle DD, Mancianti ML, Cline P, and Hincenbergs M (1990). Calcium regulation of growth and differentiation of normal human keratinocytes: Modulation of differentiation competence by stages of growth and extracellular calcium. J Cell Physiol 143:294-302.

Porter RM, Hutcheson AM, Rugg EL, Quinlan RA, and Lane EB (1998). cDNA cloning, expression and assembly charateristics of mouse keratin 16. J Biol Chem 273:32265-32272.

Purkis PE, Steel JB, Mackenzie IC, Nathrath WBJ, Leigh IM, and Lane EB (1990). Antibody markers of basal cells in complex epithelia. J Cell Sci 97:39-50.

Rugg EL, McLean WHI, Lane EB, Pitera R, McMillan JR, Dopping-Hepenstal PJC, Navsaria HA, Leigh IM, and Eady RAJ (1994). A functional "knockout" of human keratin 14. Genes Dev 8:2563-2573.

Ryle CM, Breitkreutz D, Stark H-J, Leigh IM, Steinert PM, Roop D, and Fusenig NE (1989). Density-dependent modulation of synthesis of keratins 1 and 10 in the human keratinocyte line HACAT and in ras-transfected tumorigenic clones. Differentiation 40:42-54.

Sasaki K, Murakami T, Kawasaki M, and Takahashi M (1987). The cell-cycle associated change of the Ki-67 reactive nuclear antigen expression. J Cell Physiol 133:579-584.
Scott RJ, Hall PA, Haldane JS, van Noorden S, Price Y, Lane DP, and Wright NA (1991). A comparison of immunohistochemical markers of cell proliferation with experimentally determined growth fraction. J Pathol 165:173-178.

Smedts F, Ramaekers F, Leube RE, Keijser K, Link M, and Vooijs $P(1993)$. Expression of keratin-1, keratin-6, keratin-15, keratin-16, and keratin-20 in normal cervical epithelium, squamous metaplasia, cervical intraepithelial neoplasia, and cervical-carcinoma. Am J Pathol 142:403-412.

Stasiak PC, Purkis PE, Leigh IM, and Lane EB (1989). Keratin 19-predicted amino acid sequence and broad tissue distribution suggest it evolved from keratinocyte keratins. J Invest Dermatol 92:707-716.

Swensson O, Langbein L, McMillan JR, Stevens HP, Leigh IM, McLean WHI, Lane EB, and Eady RAJ (1998). Specialised keratin expression pattern in human ridged skin as an adaption to high physical stress. Brit J Dermatol 139:767-775.

Waseem A, Dogan B, Tidman N, Alam Y, Purkis P, Jackson S, Lalli A, Machesney M, and Leigh IM (1999). Keratin 15 expression in stratified epithelia: Downregulation in activated keratinocytes. J Invest Dermatol 112:362-369.

Watt FM, Mattley DL, and Garrod DR (1984). Calciuminduced reorganization of desmosomal components in cultured human keratinocytes. J Cell Biol 99:2211-2215.

Weiss R, Eichner R, and Sun TT (1984). Monoclonal antibody analysis of keratin expression in epidermal diseases: A 48and 56-kdalton keratin as molecular markers for hyperproliferative keratinocytes. J Cell Biol 98:1397-1406.

Werner S, Werner S, and Munz B (2000). Suppression of keratin 15 expression by transforming growth factor $\beta$ in vitro and by cutaneous injury in vivo. Exp Cell Res 254:80-90.

Whitbread LA and Powell BC (1998). Expression of the intermediate filament keratin gene, $\mathrm{K} 15$, in the basal cell layers of epithelia and the hair follicle. Exp Cell Res 244:448459.

Wilson CL, Dean D, Lane EB, Dawber RPR, and Leigh IM (1994). Keratinocyte differentiation in psoriatic scalp: Morphology and expression of epithelial keratins. Brit J Dermatol 131:191-200. 